\title{
Pleural effusion in a child with a ventriculoperitoneal shunt and congenital heart disease
}

\author{
Jennifer Henningfeld ${ }^{1 *}$, Rohit S. Loomba², Santiago Encalada' ${ }^{1}$, Kristin Magner $^{3}$, Jennifer Pfister ${ }^{3}$,
} Anne Matthews ${ }^{4}$, Andrew Foy ${ }^{4}$ and Theresa Mikhailov ${ }^{3}$

\begin{abstract}
We present the unique case of an 8 month old infant who required extracorporeal membrane oxygenation (ECMO) after neonatal repair of tetralogy of Fallot. While on ECMO, he developed grade 3 intraventricular hemorrhage resulting in hydrocephalus requiring ventriculoperitoneal (VP) shunt placement at 5 months of life. He presented to cardiology clinic with a 2-month history of poor weight gain, tachypnea, and grunting and was found to have a large right sided pleural effusion. This was proven to be cerebrospinal fluid (CSF) accumulation secondary to poor peritoneal absorption with subsequent extravasation of CSF into the thoracic cavity via a diaphragmatic defect. After diaphragm repair, worsening ascites from peritoneal malabsorption led to shunt externalization and ultimate conversion to a ventriculoatrial (VA) shunt. This is the second reported case of VA shunt placement in a child with congenital heart disease and highlights the need to consider CSF extravasation as the cause of pleural effusions in children with VP shunts.
\end{abstract}

Keywords: Effusion, Shunt, Ventriculoperitoneal, Ventriculoatrial, Congenital heart disease

\section{Case report}

We present the case of an 8 months old diagnosed postnatally with tetralogy of Fallot (TOF). Permission to report the following medical and personal information was obtained from the parents of the patient.

He underwent neonatal repair due to early cyanotic spells that were not oxygen responsive. Subsequent to his cardiac repair, he required extracorporeal membrane oxygenation (ECMO) support for right ventricular dysfunction and permanent pacemaker placement for atrioventricular block. While on ECMO, the infant developed grade 3 intraventricular hemorrhage (IVH) and resulting hydrocephalus, requiring placement of a ventriculoperitoneal shunt (VP) shunt at 5 months old. Due to the degree of systemic right ventricular dysfunction and the

\footnotetext{
*Correspondence: JHenningfeld@mcw.edu

${ }^{1}$ Department of Pulmonary and Sleep Medicine, Children's Hospital of Wisconsin/Medical College of Wisconsin, 9000 W. Wisconsin Ave MS B620, Milwaukee, WI 53226, USA

Full list of author information is available at the end of the article
}

immediate need for elevated cardiac support, creating an atrial septal defect was not considered to be a reasonable approach.

At 8 months old, he presented to cardiology clinic with mild respiratory distress reportedly starting 2 months prior. He also had suboptimal weight gain over the previous 2 months despite adequate caloric intake. On exam he was tachypneic and was saturating above $90 \%$. A complete metabolic panel was normal except for a bicarbonate level of 17.1. Brain natriuretic peptide was 137, down trending since his TOF repair. A complete blood count and erythrocyte sedimentation rate were normal; his initial capillary blood gas demonstrated carbon dioxide partial pressure of 33.1. A chest radiograph revealed a right sided pleural effusion with intact left-sided VP shunt catheter. The infant was admitted to the pediatric intensive care unit (PICU) for further evaluation and management of the effusion.

A right pleural chest tube was placed, resulting in marked improvement in the infant's work of breathing. Continued daily output in excess of $400 \mathrm{cc}$ raised concern

\section{至 Springer}

(c) 2016 Henningfeld et al. This article is distributed under the terms of the Creative Commons Attribution 4.0 International License (http://creativecommons.org/licenses/by/4.0/), which permits unrestricted use, distribution, and reproduction in any medium, provided you give appropriate credit to the original author(s) and the source, provide a link to the Creative Commons license, and indicate if changes were made. 
for diaphragmatic defect with extravasation of fluid from the abdomen into the thorax.

Pleural fluid analysis demonstrated a transudative profile with elevated beta 2 transferrin levels consistent with cerebrospinal fluid (CSF). The decision was made for diaphragmatic exploration and drainage of the right pleural effusion. Exploration revealed a right sided diaphragmatic hernia with omentum and CSF in the right pleural cavity and the hernia was repaired.

Following diaphragm repair, the infant had abdominal distention, discomfort, and grunting. These symptoms raised concern for impaired peritoneal absorption of CSF producing increased abdominal pressure now that no diaphragmatic defect allowed for decompression. Abdominal ultrasound demonstrated diffuse fluid throughout the abdomen and pelvis. Shunt externalization and drainage of peritoneal fluid improved the distention and respiratory distress.

After monitoring central venous pressure (CVP) for several days, his right atrial pressure was determined amenable for ventriculoatrial (VA) shunt placement. CVPs ranged from 10 to $12 \mathrm{mmHg}$ during this period. It was believed that these were elevated due to residual right ventricular dysfunction. The infant tolerated VA shunt placement and was discharged with no respiratory or abdominal symptoms. He continues to follow-up in cardiology and neurosurgery clinic without concern.

\section{Discussion}

We present the case of an infant with TOF requiring neonatal repair and postoperative ECMO support. IVH while on ECMO led to hydrocephalus requiring VP shunt placement. This shunt had to be converted to a VA shunt due to poor peritoneal absorption of CSF, a phenomenon recognized by a persistent right sided pleural effusion secondary to a diaphragmatic hernia.

This is the second reported case of VA shunt placement in a child with congenital heart disease (CHD), the first in a patient with TOF. The first patient was a 15 -yearold girl with a history of congenital pulmonary stenosis and aortic insufficiency. A VP shunt for hydrocephalus was placed at 2 years of age, but at age 15 she underwent colectomy for juvenile colonic polyposis. Postoperatively, ascites developed, requiring VP to VA shunt conversion. During reported follow-up she did well with no cardiac or shunt-related issues (Niggemann et al. 1990).

In the reported case, the decision to perform a complete neonatal repair was made based on our institutional practice to proceed with neonatal repair in infants without contraindications for cardiopulmonary bypass. This has become standard practice at our institution for patients requiring neonatal intervention as good outcomes have been achieved with this strategy without the risk of systemic to pulmonary shunt clot. At our institution, we have found no difference in perioperative factors such as bypass time, cross clamp time, and deep hypothermic circulatory arrest time for neonatal versus non-neonatal repair, with or without earlier palliation. In follow-up we have found only a mild increase in need for a trans-annular patch and postoperative arrhythmias. This increase in risk is lower than that of a systemic to pulmonary shunt clot while awaiting complete repair.

The question in CHD patients becomes whether the right heart will tolerate the additional volume load due to CSF drainage. If cardiac function is normal, it is unlikely that this volume should be an issue. In our case, the daily CSF output was approximately $300 \mathrm{cc}$ after shunt externalization. In the setting of normal right ventricular function with a cardiac output of at least $2500 \mathrm{ml} / \mathrm{min}$, this rate of drainage would increment his cardiac output to $2500.2 \mathrm{ml} / \mathrm{min}$. A VA shunt is associated with an additional minor volume load when compared to a VP shunt or physiological resorption of CSF into the sagittal sinus since there is now a direct connection into the atrium. While CSF absorbed in the peritoneum may eventually return to the heart via the lymphatic system and the caval veins, the direct volume burden associated with this is felt to be lower than that of a shunt draining directly into the atrium.

The additional volume burden on the heart being negligible, the next issue becomes the risk of right heart failure, which can cause an increased CVP and, theoretically, reduce CSF flow down the shunt. If the CVP increased above that of the cerebral ventricle, this pressure differential would prevent adequate CSF drainage and lead to elevated intracranial pressure. Therefore, VA shunt placement in a patient with right-sided heart failure and increased CVP may be ineffective for controlling hydrocephalus. On the other hand, in surgically palliated CHD, CVPs often range from 5 to $12 \mathrm{mmHg}$ with normal right ventricular function. As normal pressures throughout the intracranial ventricular system range from 10 to $20 \mathrm{mmHg}$, the CSF pressure should exceed the CVP in most patients with CHD (Gilland 1969).

While the hemodynamics in patients with CHD seems amenable to placement of a VA shunt, there are additional considerations regarding their long-term consequences. Specifically, there are case reports and case series describing development of pulmonary hypertension in patients with VA shunts. This is believed to be secondary to chronic thromboembolic events damaging the pulmonary vasculature (Kim and Lang 2012; Kluge et al. 2009, 2010; Vernet and Rilliet 2001; Pascual and Prakash 1993; Piatt and Hoffman 1989; Drucker et al. 1984; Fagan and Jennings 1978).

Pediatric data on this comes primarily from Piatt et al. who reported 4 cases of fatal cor pulmonale in children 
with VA shunts and otherwise normal hearts. These children died at a median age of 6 (range 2-7 years) with all demonstrating evidence of pulmonary emboli (Piatt and Hoffman 1989). Patients with right-sided CHD, such as our patient, may have a compounded risk of pulmonary hypertension and subsequent right ventricular dysfunction. Nevertheless, this is merely speculation as this is only the second reported case of a VA shunt in a child with CHD (Niggemann et al. 1990).

This case also highlights the need to consider CSF extravasation as the cause of pleural effusions in patients with VP shunts. Other conditions more classically associated with such effusions must also be addressed, including congestive heart failure, liver failure, hypoalbuminemia, nephrotic syndrome, malignancy, infection, and autoimmune disorders.

A key factor in evaluation of non-CSF pleural effusions is determining whether it is transudative versus exudative, narrowing the differential diagnosis (Villena Garrido et al. 2014). However, with CSF effusion, the fluid may be either transudative or exudative (Chuen-im et al. 2012). CSF effusion is often yellow-tinged and can be confirmed by the presence of beta- 2 transferrin, one of the most abundant polypeptides in human CSF, although false negative results have been reported (Taub and Lavyne 1994).

Pleural effusions secondary to CSF extravasation in the setting of VP shunts can occur by one of three mechanisms: (1) intrathoracic trauma during shunt placement; (2) migration of the peritoneal catheter into the thoracic cavity; (3) pleural effusion secondary to increased intraabdominal pressure due to CSF ascites (Taub and Lavyne 1994). Ours is the 38th reported case of CSF pleural effusion (Obrador and Villarejo 1977; Cooper 1978; Agha et al. 1983; Lourie and Bajwa 1985; Anegawa et al. 1986; Gaudio et al. 1988; Dickman et al. 1989; Savolaine and Khimji 1991; Meeker and Barnett 1994; Gupta and Berry 1994; Doh et al. 1995; Johnson and Maxwell 1995; Martin et al. 1997; Mayoralas Alises et al. 1999; Di Roio and Mottolese 2000; Akyuz et al. 2004; Samdani et al. 2005; Rahimi Rad et al. 2007; Kim et al. 2008; Ergun et al. 2008; Kiran et al. 2010; Glatstein et al. 2012; Globl 1978; Ceccotti et al. 1981; Trappe et al. 1988; Faillace and Garrison 1998; Hadzikaric et al. 2002; Muramatsu and Koike 2004; Adeolu et al. 2006; Born et al. 2008; Smith and Cohen 2009; Kocaogullar et al. 2011; Patel et al. 2011; Chuen-im et al. 2012; Ulus et al. 2012; Sekiguchi et al. 2013). A majority of these cases ( $58 \%$ ) were due to peritoneal catheter migration into the thorax. Nine $(24 \%)$ of these cases had associated ascites. The remainder $(18 \%)$ is assumed to be secondary to intrathoracic trauma at the time of shunt placement (Table 1).
Table 1 Summary of literature

\begin{tabular}{|c|c|c|}
\hline & Study & Etiology of effusion \\
\hline 1 & Obrador et al. & Migration of catheter \\
\hline 2 & Cooper et al. & Migration of catheter \\
\hline 3 & Agha et al. & Migration of catheter \\
\hline 4 & Lourie et al. & Migration of catheter \\
\hline 5 & Anegawa et al. & Migration of catheter \\
\hline 6 & Gaudio et al. & Migration of catheter \\
\hline 7 & Dickman et al. & Migration of catheter \\
\hline 8 & Savolaine et al. & Migration of catheter \\
\hline 9 & Meeker et al. & Migration of catheter \\
\hline 10 & Gupta et al. & Migration of catheter \\
\hline 11 & Doh et al. & Migration of catheter \\
\hline 12 & Johnson et al. & Migration of catheter \\
\hline 13 & Martin et al. & Migration of catheter \\
\hline 14 & Mayorales et al. & Migration of catheter \\
\hline 15 & Di Roio et al. & Migration of catheter \\
\hline 16 & Akyuz et al. & Migration of catheter \\
\hline 17 & Samdani et al. & Migration of catheter \\
\hline 18 & Rahimi Rad et al. & Migration of catheter \\
\hline 19 & Kim et al. & Migration of catheter \\
\hline 20 & Ergun et al. & Migration of catheter \\
\hline 21 & Kiran et al. & Migration of catheter \\
\hline 22 & Glatstein et al. & Migration of catheter \\
\hline 23 & Globl et al. & Abdominal ascites \\
\hline 24 & Ceccotti et al. & Abdominal ascites \\
\hline 25 & Trappe et al. & Abdominal ascites \\
\hline 26 & Faillace et al. & Unclear \\
\hline 27 & Hadzikaric et al. & Unclear \\
\hline 28 & Muramatsu et al. (patient 1) & Abdominal ascites \\
\hline 29 & Muramatsu et al. (patient 2) & Abdominal ascities \\
\hline 30 & Adeolu et al. & Unclear \\
\hline 31 & Born et al. & Abdominal ascites \\
\hline 32 & Smith et al. & Abdominal ascites \\
\hline 33 & Kocaogullar et al. & Unclear \\
\hline 34 & Patel et al. & Unclear \\
\hline 35 & Cheun-im et al. & Unclear \\
\hline 36 & Ulus et al. & Unclear \\
\hline 37 & Sekiguchi et al. & Abdominal ascities \\
\hline 38 & Henningfeld et al. (this study) & Abdominal ascites \\
\hline
\end{tabular}

Development of pleural effusions due to the first two mechanisms is intuitive. The third mechanism, however, requires additional pathophysiology, including ineffective peritoneal absorption of CSF, a communication from the abdominal cavity, and ineffective pleural absorption of fluid. As ascites accumulate, abdominal hydrostatic pressure increases, eventually exceeding intrathoracic pressure, forcing CSF into the thorax through a diaphragmatic 
defect. Pleural effusions persist if pleural absorption is inadequate.

Diaphragmatic defects include the hernia of Bochdalek, the hernia of Morgagni, central diaphragmatic hernia, diaphragmatic eventration, and diaphragmatic agenesis. The former two are the most common and represent over $80 \%$ of congenital diaphragmatic defects (Keijzer and Puri 2010; Schumacher and Gilbert 2009). In addition to these there are acquired diaphragmatic defects which may be secondary to previous diaphragm intervention, chest tube placement, pacemaker implantation, or VP shunt placement (Blitz and Louie 2009). In our case both chest tube placement and pacemaker implantation may have led to an acquired diaphragmatic defect.

\section{Conclusion}

We present a case of right sided pleural effusion due to CSF extravasation from the abdomen via a diaphragmatic defect in an infant with a VP shunt. Additionally, the child had TOF requiring neonatal repair, necessitating consideration of right sided cardiac hemodynamics before conversion from VP to a VA shunt. This case highlights the need to consider CSF extravasation as a cause of pleural effusion in children with VP shunts and demonstrates that VA shunts appear to be safe and effective in children with CHD and otherwise normal right ventricular function. Long-term follow up should include particular attention to the development of pulmonary hypertension which may result from thromboembolic events related to the VA shunt.

\section{Abbreviations \\ ECMO: extracorporeal membrane oxygenation; VP: ventriculoperitoneal shunt; CSF: cerebrospinal fluid; VA: ventriculoatrial; TOF: tetralogy of Fallot; IVH: intraventricular hemorrhage; CHD: congenital heart disease; PICU: pediatric intensive care unit; CVP: central venous pressure. \\ Authors' contributions \\ $J H, R L, S E, K M, J P, A M, A F$, and TM all made substantial contributions to conception of paper, were involved in drafting the manuscript and revising it critically for important intellectual content and have given final approval of the version to be published. All agree to be accountable for all aspects of the work in ensuring that questions related to the accuracy or integrity of any part of the work are appropriately investigated and resolved. All authors read and approved the final manuscript.}

\section{Author details \\ ${ }^{1}$ Department of Pulmonary and Sleep Medicine, Children's Hospital of Wisconsin/Medical College of Wisconsin, 9000 W. Wisconsin Ave MS B620, Milwaukee, WI 53226, USA. ${ }^{2}$ Department of Cardiology, Children's Hospital of Wisconsin/Medical College of Wisconsin, 9000 W. Wisconsin Ave, MS 713, Milwaukee, WI 53226, USA. ${ }^{3}$ Department of Critical Care, Children's Hospital of Wisconsin/Medical College of Wisconsin, 9000 W. Wisconsin Ave MS 681, Milwaukee, WI 53226, USA. ${ }^{4}$ Department of Neurosurgery, Children's Hospital of Wisconsin/Medical College of Wisconsin, 999 N 92nd St. Suite 310, Milwau- kee, WI 53226, USA.}

\section{Competing interests}

The authors declare that they have no competing interests.
Received: 7 October 2015 Accepted: 18 January 2016

Published online: 27 January 2016

\section{References}

Adeolu AA, Komolafe EO, Abiodun AA, Adetiloye VA (2006) Symptomatic pleural effusion without intrathoracic migration of ventriculoperitoneal shunt catheter. Child's Nerv Syst 22(2):186-188. doi:10.1007/s00381-005-1164-y

Agha FP, Amendola MA, Shirazi KK, Amendola BE, Chandler WF (1983) Unusual abdominal complications of ventriculo-peritoneal shunts. Radiology 146(2):323-326. doi:10.1148/radiology.146.2.6849079

Akyuz M, Ucar T, Goksu E (2004) A thoracic complication of ventriculoperitoneal shunt: symptomatic hydrothorax from intrathoracic migration of a ventriculoperitoneal shunt catheter. Br J Neurosurg 18(2):171-173. doi:10. 1080/02688690410001681046

Anegawa S, Yoshida M, Kuramoto S, Ohmori Y (1986) Migration of ventriculo-peritoneal shunt into the chest: case report. Neurol Med Chir 26(3):256-261

Blitz M, Louie BE (2009) Chronic traumatic diaphragmatic hernia. Thorac Surg Clin 19(4):491-500. doi:10.1016/j.thorsurg.2009.08.001

Born M, Reichling S, Schirrmeister J (2008) Pleural effusion: beta-trace protein in diagnosing ventriculoperitoneal shunt complications. J Child Neurol 23(7):810-812. doi:10.1177/0883073808314157

Ceccotti C, Colantuono C, Fontana L, Granieri U, Mauro G, Severino P (1981) Unusual case of hydrothorax, cerebrospinal fluid ascites and hydrocele in a patient with a ventriculo-peritoneal shunt. Acta Neurol 3(1):274-279

Chuen-im P, Smyth MD, Segura B, Ferkol T, Rivera-Spoljaric K (2012) Recurrent pleural effusion without intrathoracic migration of ventriculoperitoneal shunt catheter: a case report. Pediatr Pulmonol 47(1):91-95. doi:10.1002/ ppul.21510

Cooper JR (1978) Migration of ventriculoperitoneal shunt into the chest: case report. J Neurosurg 48(1):146-147. doi:10.3171/jns.1978.48.1.0146

Di Roio C, Mottolese C (2000) Ventriculoperitoneal shunt and pleural effusion. Ann Fr Anesth Reanim 19(4):333-334

Dickman CA, Gilbertson D, Pittman HW, Rekate HL, Daily WJ (1989) Tension hydrothorax from intrapleural migration of a ventriculoperitoneal shunt. Pediatr Neurosci 15(6):313-316

Doh JW, Bae HG, Lee KS, Yun IG, Byun BJ (1995) Hydrothorax from intrathoracic migration of a ventriculoperitoneal shunt catheter. Surg Neurol 43(4):340-343

Drucker MH, Vanek VW, Franco AA, Hanson M, Woods L (1984) Thromboembolic complications of ventriculoatrial shunts. Surg Neurol 22(5):444-448

Ergun R, Okten Al, Gezercan Y (2008) Hydrothorax: transdiaphragmatic migration of a ventriculoperitoneal shunt catheter. Pediatr Neurosurg 44(1):62-64. doi:10.1159/000110665

Fagan ET, Jennings GL (1978) Chronic thromboembolic pulmonary hypertension following ventriculo-atrial shunting. Aust N Z J Med 8(4):426-427

Faillace WJ, Garrison RD (1998) Hydrothorax after ventriculoperitoneal shunt placement in a premature infant: an iatrogenic postoperative complication: case report. J Neurosurg 88(3):594-597. doi:10.3171/ jns.1998.88.3.0594

Gaudio R, De Tommasi A, Occhiogrosso M, Vailati G (1988) Respiratory distress caused by migration of ventriculoperitoneal shunt catheter into the chest cavity: report of a case and review of the literature. Neurosurgery 23(6):768-769

Gilland O (1969) Normal cerebrospinal-fluid pressure. N Engl J Med 280(16):904-905

Glatstein MM, Roth J, Scolnik D, Haham A, Rimon A, Koren L, Constantini S (2012) Late presentation of massive pleural effusion from intrathoracic migration of a ventriculoperitoneal shunt catheter: case report and review of the literature. Pediatr Emerg Care 28(2):180-182. doi:10.1097/ PEC.0b013e3182447dce

Globl H (1978) Shunts and complications. Prog Pediatr Radiol 6:231-271

Gupta AK, Berry M (1994) Ventriculo-peritoneal shunt presenting with recurrent pleural effusion: report of a new complication. Pediatr Radiol 24(2):147

Hadzikaric N, Nasser M, Mashani A, Ammar A (2002) CSF hydrothorax-VP shunt complication without displacement of a peritoneal catheter. Child's Nerv Syst 18(3-4):179-182. doi:10.1007/s003810100504 
Johnson MC, Maxwell MS (1995) Delayed intrapleural migration of a ventriculoperitoneal shunt. Child's Nerv Syst 11(6):348-350

Keijzer R, Puri P (2010) Congenital diaphragmatic hernia. Semin Pediatr Surg 19(3):180-185. doi:10.1053/j.sempedsurg.2010.03.001

Kim NH, Lang IM (2012) Risk factors for chronic thromboembolic pulmonary hypertension. Eur Respir Rev 21(123):27-31. doi:10.1183/09059180.00009111

Kim HK, Seo EK, Cho YJ, Kim SJ (2008) Hydrothorax due to migration of ventriculoperitoneal shunt catheter. J Korean Neurosurg Soc 43:159-161

Kiran NA, Kasliwal MK, Suri A, Mahapatra AK (2010) Intrathoracic migration of ventriculoperitoneal shunt. Indian J Pediatr 77(3):335. doi:10.1007/ s12098-009-0293-9

Kluge S, Baumann HJ, Regelsberger J, Kehler U, Koziej B, Klose H, Greinert U, Kreymann G, Meyer A (2009) Development of pulmonary hypertension in adults after ventriculoatrial shunt implantation. Respiration 78(1):30-35. doi:10.1159/000156947

Kluge S, Baumann HJ, Regelsberger J, Kehler U, Gliemroth J, Koziej B, Klose H, Meyer A (2010) Pulmonary hypertension after ventriculoatrial shunt implantation. J Neurosurg 113(6):1279-1283. doi:10.3171/2010.6. JNS091541

Kocaogullar Y, Guney O, Kaya B, Erdi F (2011) CSF hydrothorax after ventriculoperitoneal shunt without catheter migration: a case report. Neurol Sci 32(5):949-952. doi:10.1007/s10072-011-0722-1

Lourie H, Bajwa S (1985) Transdiaphragmatic migration of a ventriculoperitoneal catheter. Neurosurgery 17(2):324-326

Martin LM, Donaldson-Hugh ME, Cameron MM (1997) Cerebrospinal fluid hydrothorax caused by transdiaphragmatic migration of a ventriculoperitoneal catheter through the foramen of Bochdalek. Child's Nerv Syst 13(5):282-284. doi:10.1007/s003810050084

Mayoralas Alises S, Gonzalez Lorenzo F, Diaz Lobato S (1999) Pleural effusion secondary to intrathoracic migration of the distal end of a ventriculoperitoneal shunt. Arch Bronconeumol 35(5):249-250

Meeker DP, Barnett GH (1994) Right pleural effusion due to a migrating ventriculoperitoneal shunt. Cleve Clin J Med 61(2):144-146

Muramatsu H, Koike K (2004) Pleural effusions appearing in the rehabilitation ward after ventriculoperitoneal shunts: a report of two adult cases and a review of the literature. Brain Inj 18(8):835-844. doi:10.1080/0269905041 0001671793

Niggemann B, Kauerz U, Petersen V, Gravinghoff L, Keck EW (1990) Massive ascites formation due to unabsorbed cerebrospinal fluid following abdominal surgery in ventriculoperitoneal shunt: a case report. Klin Padiatr 202(3):180-182. doi:10.1055/s-2007-1025515

Obrador S, Villarejo F (1977) Hydrothorax: unusual complication of ventriculoperitoneal shunts. Acta Neurochir (Wien) 39(3-4):167-172

Pascual JM, Prakash UB (1993) Development of pulmonary hypertension after placement of a ventriculoatrial shunt. Mayo Clin Proc 68(12):1177-1182
Patel AP, Dorantes-Argandar A, Raja Al (2011) Cerebrospinal fluid hydrothorax without ventriculoperitoneal shunt migration in an infant. Pediatr Neurosurg 47(1):74-77. doi:10.1159/000329629

Piatt JH Jr, Hoffman HJ (1989) Cor pulmonale: a lethal complication of ventriculoatrial CSF diversion. Child's Nerv Syst 5(1):29-31

Rahimi Rad MH, Mirzaagazadeh J, Ansarin K (2007) Supradiaphragmatic and transdiaphragmatic intrathoracic migration of a ventriculoperitoneal shunt catheter. Hong Kong Med J=Xianggang yi xue za zhi/Hong Kong Academy of Medicine 13(2):147-149

Samdani AF, Storm PB, Kuchner EB, Garonzik IM, Sciubba D, Carson B (2005) Ventriculoperitoneal shunt malfunction presenting with pleuritic chest pain. Pediatr Emerg Care 21(4):261-263

Savolaine ER, Khimji T (1991) Ventriculoperitoneal shunt failure resulting from complications of the thoracic segment of the shunt catheter: case report. Clin Imaging 15(1):35-40

Schumacher L, Gilbert S (2009) Congenital diaphragmatic hernia in the adult. Thorac Surg Clin 19(4):469-472. doi:10.1016/j.thorsurg.2009.08.004

Sekiguchi H, Suzuki J, Wetjen NM, Mullon JJ (2013) Recurrent cerebrospinal fluid (CSF) pleural effusions caused by ventriculoperitoneal (VP) shunt: a case with a successful treatment with endoscopic third ventriculostomy. Clin Neurol Neurosurg 115(7):1190-1193. doi:10.1016/j. clineuro.2012.10.018

Smith JC, Cohen E (2009) Beta-2-transferrin to detect cerebrospinal fluid pleural effusion: a case report. J Med Case Rep 3:6495. doi:10.1186/1752-1947-3-6495

Taub E, Lavyne MH (1994) Thoracic complications of ventriculoperitoneal shunts: case report and review of the literature. Neurosurgery 34(1):181183 (discussion 183-184)

Trappe BO, Schuster R, von Rohden L, Thal W (1988) latrogenic hydrothorax in a child with ventriculoperitoneal shunt for hydrocephalus internus. Kinderarztl Prax 56(7):337-340

Ulus A, Kuruoglu E, Ozdemir SM, Yapici O, Sensoy G, Yarar E, Kaya AH, Senel A, Dagcinar A (2012) CSF hydrothorax: neither migration of peritoneal catheter into the chest nor ascites: case report and review of the literature. Child's Nerv Syst 28(11):1843-1848. doi:10.1007/s00381-012-1862-1

Vernet O, Rilliet B (2001) Late complications of ventriculoatrial or ventriculoperitoneal shunts. Lancet 358(9293):1569-1570. doi:10.1016/ S0140-6736(01)06670-3

Villena Garrido V, Cases Viedma E, Fernandez Villar A, de Pablo Gafas A, Perez Rodriguez E, Porcel Perez JM, Rodriguez Panadero F, Ruiz Martinez C, Salvatierra Velazquez A, Valdes Cuadrado L (2014) Recommendations of diagnosis and treatment of pleural effusion: update. Arch Bronconeumol 50(6):235-249. doi:10.1016/j.arbres.2014.01.016

\section{Submit your manuscript to a SpringerOpen ${ }^{\odot}$ journal and benefit from:}

- Convenient online submission

- Rigorous peer review

- Immediate publication on acceptance

- Open access: articles freely available online

- High visibility within the field

- Retaining the copyright to your article

Submit your next manuscript at $>$ springeropen.com 